\title{
SELF DISCREPANCY AND SELF-ESTEEM AMONG COLLEGE STUDENTS
}

\section{Dr. B.S.Parimal}

\begin{abstract}
With the increasing technologies and every information being just a click away people have started to lose the physical touch and have been continuously moving towards shortcuts and easy accessibilities, which has been leading to the creation of discrepancies. The objective of this research is to study whether the discrepancy between Real Self and Virtual self influence on college student's Self-Esteem. Discrepancy between Real Self and Virtual self scale was developed based on review of literature and The Rosenberg Self-Esteem Scale was used to measure self esteem. A survey research questionnaire was used to collect data. Total of 209 participants were taken as sample from different colleges. Pearson product moment correlation and independent t- test was used to analyze the data. The major findings of this research were that the discrepancy between real self and virtual self leads to lower self-esteem among college students. The research will implicate to enhance college students self esteem.
\end{abstract}

Key words: discrepancy between real self and virtual self, self-esteem, College students and social media.

\section{Introduction}

Virtual self is how one portrays oneself on the virtual media or social media platforms. This would include their demographic details, details about their education and qualification, relationship status, achievements, job status, years of experience in a particular field and their profile picture. Some researchers consider Virtual Self 
as an extension of their physical self into the online world, whereas others experience it as an entirely different identity. Real self and Ideal self, both have the ability to exist together in the virtual world and the online identity reflects the aspect of self in an idealized manner and thus forming a 'Virtual Self'.

As Rogers said that we want positive regards from others, we have a strong need of being loved and valued by people because of which they switch to the virtual world to present themselves on social media comfortably and selectively, which forms their Virtual Self. As Jeremy Bailenson noted that world of new media, people spend a lot of time interacting with digital versions of one another. With this digital version they represent the best versions of themselves which causes conflicts with our real identity and that others perceive them to be. However the online identities stem from our real identities but they may or may not be the same.

Social media provides people a platform to showcase their selves in a way they want to and which further leads to forming a virtual self which may or may not differ from their real selves. In a study by Kukshinov, self-presentation was observed under the conditions of virtual reality, in which the usual relations between the various aspects of one's self may be lost, producing uncharacteristic performance. Interactions within the simulated environment of virtual reality may be experienced to such an extent that new properties of the self are obtained, bringing a change in the real behavior. The resultant performance might contradict existing social circumstances and vice versa.(Kukshinov, 2015).

Dian noted that Social media and online self-presentation: Effects on how we see ourselves and our bodies which demonstrates that social media use can affect views of the self and the body. The user on dating sites expected to continue their selfpresentation in a computer-mediated setting, their self views following online selfpresentation differed from the self-views of those who expected to continue their selfpresentation face-to-face and the online media offers the presenter to more control over self-presentation. The findings provide evidence for the mediating role of selfrelated variables (i.e., appearance investment, self-presentational efficacy and idealized self-presentation).

Self-esteem reflects a person's on the whole subjective emotional evaluation of his or her own worth. It is a judgment of oneself as well as an attitude toward the self. 
Self-esteem encompasses beliefs about oneself as well as emotional states. Smith and Mackie (2007) defined it as the self-concept is what we think about the self; selfesteem is the positive or negative evaluations of the self, as in how we feel about it. Carl Rogers (1902-1987), an advocate of humanistic psychology, theorized the origin of many people's problems to be that they despise themselves and consider themselves worthless and incapable of being loved. This is why Rogers believed in the significance of giving unconditional acceptance to a client and when this was done it could improve the client's self-esteem.

William James (1892) recognized multiple dimensions of the self, with two levels of hierarchy: processes of knowing and the resulting knowledge about the self. Observation about the self and storage of those observations by the l-self create three types of knowledge, which collectively account for the Me-self, according to James. These are the material self, social self, and spiritual self. The social self comes closest to self-esteem, comprising all characteristics recognized by others. The material self consists of representations of the body and possessions, and the spiritual self of descriptive representations and evaluative dispositions regarding the self. In the mid-1960s, sociologist Morris Rosenberg defined self-esteem as a feeling of self-worth and developed the Rosenberg self-esteem scale (RSES).

Virtual self is the created identity of a person in his or virtual world which is different from the actual self-concept or self-image of an individual that represents the ones self-esteem. However, this discrepancy between two self's might include various impact on the self-esteem of person. A research done by Selina Merley Boye on, 'The virtual self', concluded that the virtual world gives it users a chance to present a new self in front of an unknown audience which allows them to be more the person they wants to be. Hence the virtual self increases the self-esteem in the virtual world and not in the real world instead is discrepant from the actual reality of an individual. There are two sides of advancing technology. On one hand where we are growing and advancing, on the other hand these advancements leads to the growing concerns among the youth, worldwide. In the emerging era, where youngsters have been more exposed to the internet and online activity has become an important form of social interaction (Goel, subramanyam \& Kamath, 2013). The dependency of youth on the social media has reached a level that without social media the 
youngsters are not able to think about the direction of their growth (Singh, Amiri \& Sabbarwal, (2017). Social media provides them a platform where they feel powerful and are able to present themselves freely without restrictions or social norms. This freedom lead them to spend most of their time in the virtual world than the real world where they can be what they ought to be, speak freely, manage their world as they want and edit it according to their preferences. This idealized world and identity causes them to differ from the real physical world and develop a discrepancy between their real and the Virtual Self. This discrepancy in-turn raises concerns regarding physical and mental health. Therefore this study focuses on preparing a questionnaire to test the discrepancy between real and Virtual Self and its effect on the Self-Esteem.

\section{OBJECTIVE}

The objective of this research is to study whether the discrepancy between Real Self and Virtual self influence on college student's Self-Esteem.

\section{HYPOTHESIS}

1. There will be a significant negative correlation between the Discrepancy between Real Self and Virtual Self and Self-Esteem.

2. There will be significant difference between college students with higher Discrepancy between Real Self and Virtual Self and college students with lower higher Discrepancy between Real Self and Virtual Self in term of SelfEsteem

\section{METHOD}

\section{SAMPLE}

Total 209 participants both males and females of age 18 -25 years from Vadodara, Pune, Mumbai and Chennai city were taken as subjects. 100 male students and 109 female students were taken as a sample

Inclusion criteria: students aging from 18 to 25 years of age who have a profile and have been using social media platform actively daily at least for a year. 
Exclusion criteria: People of age below 18 and above 25. Students who have a profile on social media for less than a year or have not been actively using the social media daily.

\section{RESEARCH DESIGN}

A survey questionnaire was used to collect the data. The survey is a method for collecting information or data as reported by individuals. Surveys are questionnaires (or a series of questions) that are administered to research participants who answer the questions themselves. The participants were given the questionnaires and instructed to fill them carefully. Then the data was collected and analyzed. One of the scales was developed and was face validated by the experts. Other two already standardized tests were used. After the feedbacks on the questionnaire from the experts, changes were done and final questionnaire was prepared.

\section{TOOL}

\section{Discrepancy between real and virtual self}

To study the discrepancy between real and virtual self, a scale was developed based on the behavior of people on social media platforms which includes the demographic details, filters and editing tools used, posts put up, follow requests made, communicating with other and presenting themselves on such platforms. It is a five point scale 1 being never 2 being rarely 3 being sometimes 4 being often and 5 being always. There are 34 items in total. Internal Reliability (Chronbach alpha) was checked. It was found to be satisfactory 0.63. After eliminating the items which were not contributing to the questionnaire a total of 30 items are there in the questionnaire. Reverse scoring is done of items $3,8,9,27$. The final questionnaire's internal reliability (Chronbach Alpha) was found to be highly reliable 0.72 on the 30 items.

\section{Self-Esteem Scale}

The Rosenberg Self-Esteem Scale, a widely used self-report instrument for evaluating individual self-esteem, it is a 10-item scale that measures global selfworth by measuring both positive and negative feelings about the self. All items are answered using a 4-point Likert scale format ranging from 'strongly agree' to 
'strongly disagree'. It was investigated using item response theory. A unidimensional model for graded item responses was fit to the data. The test of significance indicated that the unconstrained model better fit the data-that is, the 10 items of the Rosenberg Self-Esteem Scale are not equally discriminating and are differentially related to self-esteem. The pattern of functioning of the items was examined with respect to their content, and observations are offered with implications for validating and developing future personality instruments. Reverse scoring is used for items 2, 5, 6, 8, 9, giving "Strongly Disagree" 1 point, "Disagree" 2 points , "Agree" 3 points, and "Strongly Agree" 4 points. Score between 15-25 are considered to be average. Originally the Cronbach alpha value for Rosenberg's self esteem scale is 0.849 . The current internal reliability (Cronbach Alpha) is 0.627 .

\section{PROCEDURE}

The study has been conducted on 209 people from different cities. There were a total of 100 males and 109 females of 18 to 25 years of age. The questionnaire was developed and expert validated, after which the modification were made. Google form was also made to collect the data. The participants were given the questionnaires and instructed to fill them carefully and in the Google form the instructions were mentioned. Then the data was collected and collectively analyzed.

\section{RESULT and DISCUSSION}

To study the correlation between Discrepancy between real and virtual self and Selfesteem, Pearson Product-Moment Correlation was used and the results are shown below:

Table No. 1: Indicates the correlation between Discrepancy between real and virtual self and Self-esteem:

\begin{tabular}{|l|l|l|}
\hline Pearson Correlation & DRVS & Self Esteem \\
\hline DRVS & 1 & \\
\hline Self Esteem & $-0.235^{\star *}$ & 1 \\
\hline
\end{tabular}

The Correlations between Discrepancy between real and virtual self and Selfesteem: 
There is a significant negative correlation between Discrepancy between real and virtual self and Self-esteem $(r(206)=-0.235, p<0.01)$. This means that when the discrepancy between real and virtual self of participants increases their self-esteem decreases. The first hypothesis assumes that there will be a significant negative correlation between the Discrepancy between Real Self and Virtual Self and SelfEsteem. The result (table 1) indicates a significant negative correlation between Discrepancy between real and virtual self and Self-esteem. This shows that when the discrepancy between real and virtual self of participants increases their selfesteem decreases. A study done by Jan, Soomro and Ahmad in 2017 on the Impact of social media on Self-Esteem shows how with the gained popularity of the social media have caused a long-lasting effect on the users. The upward comparisons made on such platforms have caused people to have lower Self-Esteems. The major finding from the study proved that there is a strong relationship between social media and self-esteem. With the increase in social media usage causes the self-esteem to decrease. Hence the first hypothesis accepted.

Table No. 2: Indicates influence of the level of discrepancy (high and low discrepancy) of participants on their Self Esteem.

\begin{tabular}{|l|r|l|l|l|l|}
\hline \multicolumn{2}{|l|}{ Dimensions } & Mean (SD) & DF & t & Sig. \\
\hline Self- Esteem & High discrepancy (above & 22.77 & & & \\
median) & & $(2.70)$ & & & \\
& & & 207 & 2.24 & 0.02 \\
& low discrepancy (below & 21.89 & & & \\
median) & & $(2.88)$ & & & \\
\hline
\end{tabular}

The groups were divided on the basis of the Median (MD = 49). Below 49 is lower Discrepancy between real and virtual self and above 49 is higher Discrepancy between real and virtual self. There is a significant difference between higher Discrepancy between real and virtual self (above the median) and Lower Discrepancy between real and virtual self (below the median) in terms of their SelfEsteem ( $\mathrm{t}(207)=2.24, \mathrm{p}<0.05)$. The Mean of participants who has higher Discrepancy between real and virtual self (above the median) is 22.77 (2.70) and 
participants who has lower Discrepancy between real and virtual self (below the median) is 21.89 (2.88). The participants who has higher Discrepancy between real and virtual self (above the median) have lower Self-Esteem compared to the participants who has lower Discrepancy between real and virtual self (below the median). The second hypothesis assumed that There will be significant difference between college students with higher Discrepancy between Real Self and Virtual Self and college students with lower higher Discrepancy between Real Self and Virtual Self in term of Self-Esteem. Hence the second hypothesis is accepted

\section{Limitations}

There are following limitations of study;

- $\quad$ The male female ratio was not equal.

- $\quad$ The usage time ratio was not equal.

- $\quad$ The data was collected only from the urban areas.

\section{Implications}

With the advent of this century there has been a boom in the use of technology this has spread across all age groups and affected their lives in both positive as well as negative ways. This research has found the impact of social media platform usage and creation of a virtual self which in turn affects their Self-Esteem and possible reasons why one switches to form a virtual self. The research implies in following areas:

- To study the prevalence of discrepancy between Real Self and Virtual Self. The research will implicate to enhance college students self esteem.

- The study will explain how the discrepancy between Real Self and Virtual Self has an effect on one's Self-Esteem. The research will add on to the knowledge of media psychology which is a developing branch of psychology.

\section{Conclusion}

This study concludes that when the discrepancy between real and virtual self of participants increases their self-esteem decreases. And therefore there is a significant negative correlation among the discrepancy between real and virtual self of participants and their Self-esteem. A significant difference was found when there 
Towards Excellence: An Indexed, Refereed \& Peer Reviewed Journal of Higher Education / Dr. B.S. Parimal/ Page 80-91

is high discrepancy between real self and Virtual self on their Self-Esteem. This shows that the student who engage more in social media activity in order to fulfill their self presentational desires and further building up a virtual self which is different from their Real Self, lead to a low Self-Esteem or vice versa. 


\section{References}

Anderson, M. \& Jiang J. (2018). Teens, social media \& technology 2018. Pew Research Centre- Internet and Technology. Retrived from teen mental health and the theory of social comparison. (2019, january 4). Retrieved from newport academy: http://www.newportacademy.com/resources/empowering-teens/theory-of-socialcomparison/

Bailenson, J. (2011). science nation. Retrieved from national science foundation. Retrived from https://www.nsf.gov/news/special_reports/science_nation/virtualself.jsp

Boye, S. M. (2014). The Virtual Self, exploring the influence of virtual world on selfconcept and psychological well-being: a qualitative study. Positive Psychology and Technology. Retrieved from:

http://www.google.co.in/url?sa=t\&source=web\&rct=j\&url=https://essay.utwente.nl/64 770/1/Boye $\% 252$ C $\% 2520$ S.M. $\% 2520$ \%2520s1099337\%2520\%2528verslag\%2529.pdf\&ved=2ahUKEwj1sObO37XfAhULt o8KHUEBDZIQFjAAegQIARAB\&usg=AOvVaw2rIWWnpgv0D

Brooks, L. A. (2017). Life satisfaction: a key to managing internet \&social media addiction. technology in society, 73-77.

Vigil, T.R. and H. Denis Wu (2014). Facebook users' engagement and percieved life satisfaction. media and communication, 3(1), 5-16.

Diener, E. E. (1985). The satisfaction with life scale. Journal of Personality Assessment, 71-75.

Espnes, M. (2013). Self-esteem and life satisfaction in adolescents-gender and age as potential moderators. quality in life research, 22(10). Retrieved April 2019

Goel D. Subramanyam A. \& Ravindra K. (2013). A study on the prevalence of internet addiction and its association with psychopathology in Indian adolescents. Indian Journal of Psychiatry. 55(2), 140-143.

Jan, S. (2017, august). Impact of Social Media on Self-Esteem. Europian Scientific Journal, 13(23), 329-341. Retrieved april 2019, from https://www.researchgate.net/publication/319396436_Impact_of_Social_Media_on_ Self-Esteem

Johnson, B. (2019). symbolic interaction perspective. Retrieved from study.com: https://study.com/academy/lesson/erving-goffmans-theories-impressionmanagement-dramaturgy-symbolic-interaction.html 
Jung, U.J. Y. (2018). Effects of Self-Discrepancy and Self-Schema on Young Women's Body Image and Self-Esteem after Media Image Exposure. family and consumer sciences research journal, 47(2).

Kukshinov, E. Y. (2015). The Virtual Self and Possible Immersive Consequences of Uncharacteristic Self-Presentation in the Virtual Environment. International Journal of Cyber Behavior, Psychology and Learning, 5(4), 73-82.

Metellus, M. a. (2013). the impact of social media on college students. journal of college \& character, 24(1), 21-29.

Dion N., A. (2016). The Effect of Instagram on Self-Esteem and Life. honours theses. Retrived from

https://digitalcommons.salemstate.edu/cgi/viewcontent.cgi ?article=1091\&context=ho nors_theses

New media \& virtual self. (2015). Retrieved on $12^{\text {th }}$ December 2015 , from http://prezi.com/m/xv4tow0c_b1/new-media-the-virtual-self/

Ruigrok. (n.d.). Usage of social networking sites and their effects on self-esteem. 147. Retrieved from

https://esource.dbs.ie/bitstream/handle/10788/2288/ba_ruigrok_a_2014.pdf?sequen $\mathrm{ce}=1 \&$ isAllowed $=\mathrm{y}$

Rupert, H. (2016). The Relations Among Social Media Addiction, Self-Esteem, and Life Satisfaction in University Students. social science computer review, 5(35).

Retrieved april 2019

Self-presentation (social psychology). (2019, april 22). Retrieved from IResearchNet: https://psychology.iresearchnet.com/social-psychology/self/self-presentation/

Singh M.M. Amiri M. \& Sabbarwal S. (2017). Social Media usage: Positive and Negative effects on the life style of Indian Youth. Iranian Journal of Social Sciences and Humanities Research. 5(3). 123-127.

Smeets. (2017). How social media use influences our life satisfaction Research on the effect of social media use on adolescents' life satisfaction and mediating mechanisms. Faculty of Social and Behavioural Sciences Theses. Retrieved April 2019, from https://dspace.library.uu.nl/handle/1874/367958

Social media. (2019, april 13). Retrieved from wikipedia: https://en.wikipedia.org/wiki/Social_media

Tanney, a. (2015, june 18). Social Comparison Theory: How Our Social Media Habits Make Us Unhappy. Retrieved april 2019, from elite daily: https://www.elitedaily.com/life/media-affects-self-worth/1055695

Vries, D. A. (n.d.). Social media and online self-presentation: Effects on how we see ourselves and our bodies. Retrieved from 
http://www.uva.nl/binaries/content/assets/uva/en/research/phd/summaries/2014/06/s ummary-de-vries.pdf

What is self? (n.d.). Retrieved on $7^{\text {th }}$ Novemebr, 2020 from:

http://www.google.co.in/url?sa=t\&source=web\&rct=j\&url=http://download.nos.org/srs ec328newE/328EL16.pdf\&ved=2ahUKEwiPvIPX1LXfAhWKvY8KHaaxD1kQFjAAeg QIBhAB\&usg=AOvVaw0gv925r4UyYAKO0vAcniF\&cshid=1545558613700

\section{Dr. B.S.Parimal \\ Assistant Professor \\ Department of Psychology, Faculty of Education and Psychology The Maharaja Sayajirao University of Baroda Vadodara}

